\title{
Production and refinement of oil from carp (Cyprinus carpio) viscera
}

\author{
Valéria Terra Crexi, Mauricio Legemann Monte, Leonor Almeida de Souza Soares, \\ Luiz Antonio Almeida Pinto*
}

Unit Operations Laboratory, School of Chemistry and Food, Federal University of Rio Grande, Rio Grande, RS, Brazil

\section{A R T I C L E I N F O}

\section{Article history:}

Received 1 November 2008

Received in revised form 26 April 2009

Accepted 30 July 2009

\section{Keywords:}

Carp oil

Ensilage process

Fishmeal process

Refined oil

\begin{abstract}
A B S T R A C T
Carp viscera oil can be obtained by both ensilage and fishmeal processes. This study examined the refinement of carp (Cyprinus carpio) oils obtained by both processes, and compared crude, neutralised, bleached, winterised and deodorised oils' characteristics and lipid profiles. Refined oils obtained by the two processes did not present significant difference $(p>0.05)$ for Lovibond colour, free fatty acids, and thiobarbituric acid values. The major fatty acids identified in the carp crude, bleached and refined oils were oleic, palmitic, palmitoleic, linoleic and linolenic, constituting approximately 69.6\% of the total fatty acids of the oils. The $n-3 / n-6$ ratio was approximately 1.05 for refined oil. Therefore, carp viscera refined oil can be considered a rich source of essential fatty acids of the $n-3$ and $n-6$ series.
\end{abstract}

(c) 2009 Published by Elsevier Ltd.

\section{Introduction}

The common carp (Cyprinus carpio) is a major fish species in world aquaculture production. It is exclusively farmed in traditional extensive or semi-intensive pools (Vandeputte et al., 2008). Therefore, there is potential for producing oil from their by-products, including heads, skins, skeletons and viscera. There are reports on production of good quality fish oils from herring (Aidos et al., 2003) and catfish (Sathivel, Prinyawiwatkul, King, Grimm, \& Lloyd, 2003) by-products. Fish oils are considered the major commercial source of eicosapentaenoic acid (EPA) and docosahexaenoic acid (DHA), and have received much attention in the scientific and industrial communities because of their positive role in human health (Fournier et al., 2007; Zhong, Madhujith, Mahfouz, \& Shahidi, 2007).

Fish oil can be obtained by the ensilage acidification process (Reece, 1981; Zhou, Paulson, \& Ackman, 1995) or by the fishmeal process (Zhong et al., 2007). However, crude oils require purification in order to meet standards for quality oil production and generation of a product acceptable for human consumption (Hafidi, Pioch, \& Ajana, 2005). The refinement operations remove undesirable components, thus guaranteeing satisfactory purity and stability characteristics (acidity, colour, oxidative and sensorial).

The chemical or alkaline refinement includes the following steps: degumming, which removes gums; neutralisation with caustic soda for free fatty acids (FFA) removal; washing, drying

\footnotetext{
* Corresponding author. Address: FURG, 475 Engenheiro Alfredo Huch Street, CEP 96201-900, Rio Grande, RS, Brazil. Tel.: +55 53 32338645; fax: +55 5332338745 .

E-mail address: dqmpinto@furg.br (L.A.A. Pinto).
}

and bleaching for removal of soap and trace metals; and deodorisation by vacuum distillation for removal of residual FFA, aldehydes, ketones, alcohols and other compounds (Antoniassi, Esteves, \& Meirelles, 1998; Berdeaux et al., 2007; Hafidi et al., 2005). Winterisation is an additional step in oil refinement, and is used for concentrating PUFAs, especially eicosapentaenoic acid and docosahexaenoic acid (Ganga et al., 1998).

The $n-3$ polyunsaturated fatty acids (PUFA), especially $(C 20: 5 n-3)$ and (C22:6n-3), have biochemical effects on the prevention or treatment of several human diseases. EPA is the precursor of prostaglandins, thromboxanes and leukotrienes. DHA is a component of the phospholipid membrane of brain and retina cells; consequently, it is essential for human health (Fournier et al., 2007; Zhong et al., 2007).

The lipid classes and fatty acid profiles of major fish species and their muscle tissues have been determined; however, there are very few studies on lipid classes and fatty acid profiles of viscera and other by-products (Zhong et al., 2007). In view of these facts, it seems necessary to carry out a study on the characteristics and fatty acid profile of crude and refined oils extracted from carp viscera. The objectives of this work were to study the refinement of carp (Cyprinus carpio) viscera crude oils obtained by ensilage acidification and fishmeal processes, and to compare their characteristics and lipid profiles.

\section{Materials and methods}

Carp (Cyprinus carpio) viscera, from fish of approximately the same size (average weight $1.30 \mathrm{~kg}$ ) and age (over 2 years old), from a commercial fish-processing plant, was utilised as raw material 
for oil extraction by ensilage and fishmeal processes; these residues were transported and immediately frozen in plastic containers at the Unit Operations Laboratory/FURG.

\subsection{Ensilage acid process methodology}

Initially, $35 \mathrm{~kg}$ of carp viscera were thawed overnight at ambient temperature and minced in a meat grinder, conditioned in 5 L plastic buckets and soon afterwards acidified with glacial acetic acid $10 \%(\mathrm{v} / \mathrm{w})$; also, BHT antioxidant (250 ppm) was added to reduce lipid oxidation. During the initial liquefaction period, the silage was stirred occasionally. Temperature during liquefaction ranged from 25 to $35^{\circ} \mathrm{C}$. After a 15-day period the silage was sifted in a 14 tyler sieve for removal of spines and scales, for subsequent centrifugation.

Silage temperature was increased to $50^{\circ} \mathrm{C}$ in a thermostatic bath afterwards, the material was separated in a centrifuge for $20 \mathrm{~min}$ at $7000 \mathrm{~g}$. The resulting product included three fractions: the bottom solid cake, an aqueous middle layer, and the upper oil layer. Oil fractions were separated from the other fractions and stored in an amber bottle at $-20^{\circ} \mathrm{C}$ for analysis.

\subsection{Fishmeal process methodology}

Processing of raw viscera was carried out for crude oil extraction on a laboratory scale, in conditions similar to commercial fish-processing plants. Processing included grinding, cooking, screening and centrifugation.

Prior to the fishmeal process, $35 \mathrm{~kg}$ of carp viscera were thawed overnight at ambient temperature and minced in a meat grinder. Afterwards, the raw material was cooked at $95-100^{\circ} \mathrm{C}$ for $30 \mathrm{~min}$. It was then sifted in a 14 tyler sieve for removal of spines and scales. Centrifugation of material for separation of fractions and storage of the oil fraction were carried out under conditions similar to the ensilage process.

\subsection{Oil refinement methodology}

The steps of the crude oil refinement process (degumming, neutralisation, washing, drying, bleaching, winterisation and deodorisation) were carried out employing the operating conditions described below.

The degumming step was carried out for $30 \mathrm{~min}$ at $80{ }^{\circ} \mathrm{C}$ and $500 \mathrm{rpm}$ agitation, with addition of $1.0 \%$ of phosphoric acid $(85 \%$ $\mathrm{v} / \mathrm{v}$ ) in relation to the oil mass. The neutralisation step occurred for $20 \mathrm{~min}$, at $40^{\circ} \mathrm{C}$ and agitation of $500 \mathrm{rpm}$, with addition of sodium hydroxide solution $(20 \% \mathrm{w} / \mathrm{w}$, using $4.0 \%$ of excess in relation to the acidity value after the degumming step). After each step, material was centrifuged for $20 \mathrm{~min}$ at $7000 \mathrm{~g}$ for oil separation.

The washing step consisted of adding $10 \%$ water in relation to the oil mass, at $95{ }^{\circ} \mathrm{C}$, for a contact time of $10 \mathrm{~min}$, with $500 \mathrm{rpm}$ agitation and oil temperature maintained at $50^{\circ} \mathrm{C}$. This step was repeated three times. The drying step lasted for 20 min with temperature at $90-95{ }^{\circ} \mathrm{C}$ and $500 \mathrm{rpm}$ agitation. The bleaching step was carried out at $70^{\circ} \mathrm{C}$ and $40 \mathrm{rpm}$, with the addition of $5 \%$ of adsorbents (mixture of activated earth and activated coal at a 9:1 ratio), with a contact time of $20 \mathrm{~min}$. Filtration was carried out in a Büchnner funnel with a pre-layer of diatomaceous earth. The refining steps (degumming, neutralisation, washing, drying and bleaching) were carried out at a manometric pressure in a vacuum of approximately $720 \mathrm{~mm} \mathrm{Hg}$.

The winterisation step was accomplished in three stages. First, the nucleation process occurred in a refrigerated bath with a water and alcohol mixture, from $30^{\circ} \mathrm{C}$ to $5^{\circ} \mathrm{C}$, with a refrigeration rate of $0.62{ }^{\circ} \mathrm{C} / \mathrm{min}$ and agitation of $500 \mathrm{rpm}$. In the second and third stages, the crystallisation processes were carried out without agi- tation, from $5^{\circ} \mathrm{C}$ to $-4{ }^{\circ} \mathrm{C}$ with a refrigeration rate of $2.7^{\circ} \mathrm{C} / \mathrm{h}$, and from $-4{ }^{\circ} \mathrm{C}$ to $-5^{\circ} \mathrm{C}$ with a refrigeration rate $0.25^{\circ} \mathrm{C} / \mathrm{h}$, respectively. Crystallisation must be driven under slow refrigeration in order to supply large crystals and stable polymorphic forms. Small crystals, formed from fast refrigeration, cannot be easily filtered. Separation of the liquid olein and solid stearin fractions was carried out by centrifugation at $7000 \mathrm{~g}$ for $20 \mathrm{~min}$.

In the deodorisation step, oil was loaded in a vessel under vacuum (750 mm Hg) with one opening connected to a condenser, in order to remove the volatiles from the system. This vessel also possessed a steam inlet, provided by a steam boiler, with a valve controlling the outflow. Deodorisation of the winterised oil was carried out at $220^{\circ} \mathrm{C}$ for $60 \mathrm{~min}$ with $5 \%$ steam (based on oil mass).

\subsection{Analytical methodology}

Free fatty acids (FFA, Ca 5a-40) and peroxide value (PV, Cd 8-53) were determined according to American Oil Chemists Society (AOCS) (1980) methodologies. The anisidine value (AV, Cd 18-90) and phosphorus content (PC, Ca 12-55) were determined according to American Oil Chemists Society (AOCS) (1997) methodologies.

FFA method was used, based on titration with a sodium hydroxide solution (phenolphthalein as an indicator) of the oil, suitably diluted with an ethyl alcohol-ethyl ether mixture. Results are expressed in \% oleic acid.

The peroxide value method was used, based on titration with a sodium thiosulfate solution of the oil diluted with an acetic acidchloroform mixture and then treated with potassium iodide. Results are expressed as milliequivalents $/ \mathrm{kg}$ oil.

The anisidine value (AV) was determined in fish oil using a spectrophotometer (Quimis model Q-108DRM, Quimis, Diadema, Brazil), based on the reaction between $\alpha$ - and $\beta$-unsaturated aldehydes (primarily 2-alkenals) and p-anisidine reagent. AV is expressed as 100 times the absorbance measured at $350 \mathrm{~nm}$ in a 1$\mathrm{cm}$ path length cuvette.

Thiobarbituric acid value (TBA) was determined according to Vyncke (1970). TBA was determined using a spectrophotometric method, calculated from a standard curve obtained by reacting known amounts of 1,1,3,3 tetramethoxypropane with TBA. Results are expressed as mg malonaldehyde/ $\mathrm{kg}$ oil.

Phosphorus content (PC) was determined in fish oil using a spectrophotometric method (Quimis model Q-108DRM).

Oil colour was determined, using the Lovibond method (Lovibond Colour Staler Tintometer, Model F, England), as described by Windsor and Barlow (1984), fixing the colour yellow at 30 units and varying the colour red.

The analyses of FFA, PV, AV, TBA, PC and colour were done in crude, degummed, neutralised, bleached, winterised and deodorised oils, in triplicate.

For fatty acid identification and quantification, chromatographic analysis was carried out for crude, bleached and refined carp oils. Fatty acid profiles were determined by preparation of methyl esters as described by Metcalfe and Schimitz (1966).

The fatty acid methyl esters (FAME) were identified by gas chromatography (Varian 3400 CX, Palo Alto, CA) equipped with an Agilent DB-23 (Santa Clara, CA) capillary column $(60 \mathrm{~m} \times 0.25 \mathrm{~mm}$, $0.25 \mu \mathrm{m}$ film thickness). FAME analysis was carried out, in duplicate, by injecting $1.0 \mu \mathrm{l}$; split ratio 1:50). GC conditions were as follows: injection temperature $215^{\circ} \mathrm{C}$, flame ionisation detector temperature $215^{\circ} \mathrm{C}$, flow rate of helium carrier gas $1.0 \mathrm{ml} / \mathrm{min}$ and linear speed $24 \mathrm{~cm} / \mathrm{s}$, oven temperature held at $110^{\circ} \mathrm{C}$ for $5 \mathrm{~min}$, then increased to $215^{\circ} \mathrm{C}$ at $5{ }^{\circ} \mathrm{C} / \mathrm{min}$ and held at $215^{\circ} \mathrm{C}$ for $24 \mathrm{~min}$. The FAME were identified by direct comparison of their retention times with standards (NU-CHEK GLC-87), and were quantified as the percentage area of each FAME mixture. 


\subsection{Statistical methodology}

Characterisation values for the carp crude, neutralised, degummed, bleached, winterised and deodorised oils, as well as fatty acid profiles and lipid classes, were compared using the Tukey HSD test of differences of means (Box, Hunter, \& Hunter, 1978), with Statistica 6.0 (Statsoft, Tulsa, OK). Values were considered significant at $p<0.05$.

\section{Results and discussion}

\subsection{Fish oil characteristics}

Table 1 presents free fatty acids percentage (FFA), peroxide value (PV), anisidine value (AV), thiobarbituric acid (TBA), phosphorus content (PC) and Lovibond colour (LC) values for carp crude, degummed, neutralised, bleached, winterised and deodorised oils obtained by fishmeal and ensilage processes. Also in this table are comparisons of oil characteristics by Tukey test of differences of means.

Crude oils obtained (Table 1 ) possessed significant differences $(p<0.05)$ for FFA, AV, TBA, PC and LC between processes. The PV values for both processes were not significantly difference $(p>0.05)$. For both processes FFA, PV, AV, TBA, PC and LC values were significantly affected $(p<0.05)$ by neutralisation oils.

Crude oil obtained by the ensilage possessed higher FFA values than crude oil produced by the fishmeal process (Table 1). FFA contents are usually associated with undesirable flavour and textural changes when they are present in fats and oils. In the oil processing industry, FFA are determined for providing an indication of the amount of alkali to be used for their removal as soaps during the refinement process (Sathivel et al., 2003).

The initial FFA content in ensilage crude oil is due to action of endogenous enzymes present in the viscera prior to acidification (Reece, 1981). Zhou et al. (1995) studied the FFA content of lipids during ensilage acidification of minced herring; in this study, the maximum FFA level was about 6\%. FFA content of fishmeal crude oil presented in Table 1 is similar to the one found by Chantachum, Benjakul, and Sriwirat (2000). The authors studied the separation and quality of fish oil from precooked and non-precooked tuna heads, obtaining FFA of approximately $3 \%$ for oils separated from non-precooked heads heated at $95{ }^{\circ} \mathrm{C}$ for $30 \mathrm{~min}$.

In Table 1 it is observed that there was a significant difference $(p<0.05)$ between the crude and degummed oils in the two processes. It can also be verified that there was an increase in FFA and $L C$ values. Therefore, the degumming step effectively removed PC and decreases in PV, AV, TBA occurred after oil degumming. Traces of phosphoric acid remaining in the oil after acid degumming treatment are responsible for the increase of acidity observed in the degummed oil. The reduction in PV, AV, and TBA was probably due to absorption of primary and secondary oxidation compounds by the hydrated gum.

For neutralised, bleached, winterised and deodorised oils (Table 1) obtained by both processes, there was observed a decrease of FFA in relation to the crude oil; this is consistent with the function of the neutralisation step, which is to remove most of the FFA; in the bleaching step, removal of the soapstocks residues occurred (Rossi, Gianazza, Alamprese, \& Stanga, 2003), and during the deodorisation step, vaporisation of odoriferous compounds and free fatty acids took place (Ceriane and Meirelless, 2007). Under appropriate processing conditions, FFA can be reduced by up to $50 \%$ during deodorisation. An acceptable level of FFA in refined fish oil is between $1.8 \%$ and $3.5 \%$ (Sathivel et al., 2003).

The winterised oils (Table 1$)$ did not differ $(p>0.05)$ between both processes. The winterisation step is used to concentrate PU-
FAs (Ganga et al., 1998). In addition, the parameters analysed in Table 1 not are affected by winterisation.

The first stage of the oxidation process is characterised by the production of hydroperoxides, which is usually measured as the peroxide value (Aidos et al., 2003). After degumming and neutralisation steps, the bleached and winterised oils obtained through the fishmeal and ensilage processes possess PV in relation to the crude oil of $47 \%$ and $43 \%$, respectively. This is consistent with the function of the bleaching earth to remove impurities, such as primary oxidation products. The removal of these impurities improves the sensory quality and oxidative stability of the refined oil (Rossi et al., 2003). The PV is below the demanded level for human consumption of $8 \mathrm{meq} / \mathrm{kg}$ oil (Boran, Karaçam, \& Boran, 2006), and for both crude oils provides an index of oxidative quality.

In the present study, anisidine values (AV) and thiobarbituric acid (TBA) values of the fishmeal crude oil were higher than values of ensilage crude oil (Table 1); this was due to the use of high temperatures during the fishmeal manufacturing process, which potentially causes increased oxidation. After degumming and neutralisation steps, the bleached and winterised oils obtained by both processes were lower in AV in relation to the crude oil by approximately $65 \%$ and $72 \%$, respectively. It was observed that TBA reduction in relation to the crude oil was approximately $79 \%$ and $71 \%$, respectively.

AV is associated with the second stage of oxidation represented by further degradation of lipids through a radical oxidation process initiated by hydroperoxides. The resulting nonvolatile secondary end-products (high molecular weight saturated and unsaturated carbonyl compounds; Aidos et al., 2003). TBA value is widely used as an indicator of the degree of lipid oxidation, with the decomposition of hydroperoxides and formation of secondary products of oxidation such as aldehydes, ketones and alcohols (Boran et al., 2006). An acceptable AV for good-quality crude fish oils is lower than 20 (Hamilton, Kalu, McNeill, Padley, \& Pierce, 1988). In Table $1, \mathrm{AV}$ values for deodorised oils were similar to results cited by Aidos et al. (2003), of 8.9 for herring oil. The TBA value in Table 1 is in agreement with the demanded patterns for quality and acceptability of oils for human consumption, of 7-8 $\mathrm{mg}$ malonaldehyde $/ \mathrm{kg}$ oil (Boran et al., 2006). In this manner, AV value and thiobarbituric acid value for both deodorised oils indicate good oxidative quality.

In the deodorised oils there is an increase in PV, AV and TBA, in relation to the bleached and winterised oils. The increase of values is due to the high temperatures used in the deodorisation step. Increased exposure of the oil to heat will increase the susceptibility to oxidation and peroxide formation, and decomposition of hydroperoxides, with the formation of secondary products of oxidation, such as aldehydes, ketones and alcohols (Ceriane \& Meirelless, 2007; Manral, Pandey, Jayathilakan, Radhakrishna, \& Bawa, 2008).

In the degumming step the phosphorus content (Table 1 ) in oils obtained by ensilage and fishmeal processes decrease by approximately $53 \%$ and $52 \%$, respectively. After the neutralisation step, all phosphorus was removed. Values for crude oils were lower than results cited by Immanuel, Sathaivan, Shankar, Peter and Palavesam (2009), for Sufflamen capistratus oil (343 ppm). Sathivel et al. (2003) studied the oil production from catfish viscera and found phosphorus concentrations of $107.6 \mathrm{ppm}$ and $99.2 \mathrm{ppm}$ in crude oil and degummed oil (citric acid), respectively. After the neutralisation step the phosphorus was removed.

Lovibond colour (LC) was higher in ensilage crude oil than that obtained by fishmeal process (Table 1). Oil pigmentation during ensiling is shown to be caused by the release of the acid hydrolysis product of haemoglobin, haem (Reece, 1981). In ensilage oil an increase in free fatty acids (FFA) content occurs, resulting in formation of lipid-protein complexes, and consequently increasing colour. 


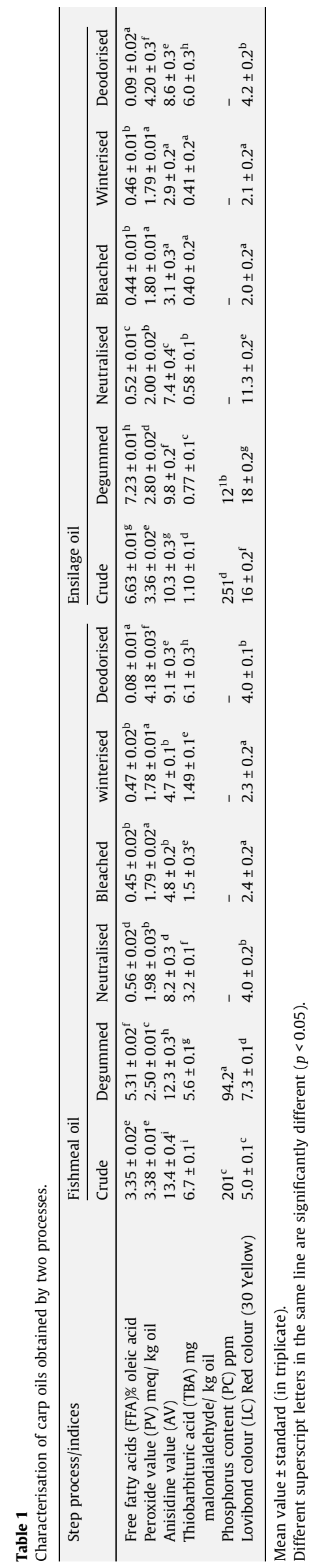

In Table 1 , a decrease in LC in relation to the crude oil can be observed for after neutralisation and bleaching. The decrease in LC in bleached oils is due to the fact that the adsorbents used for bleaching can remove pigments and other impurities, such as trace metals, phospholipids, and oxidation products (Rossi et al., 2003). However, the increase in LC in refined oils and the alteration of final colour (Table 1 ) is related to the oxidation of colourless components or the existing colour pigments becoming fixed by high temperatures (Antoniassi et al., 1998).

The characteristic yellow-orange colour of fish oil is the result of deposition of dietary carotenoids (Luterotti, Franko, \& Bicanic, 1999). Carotenoids are lipid-soluble antioxidants and their biological properties are related to their structures. The single and double bonds repeated in the polyenic chain determine their antioxidant properties (Hidalgo, Brandolini, Pompei, \& Piscozzi, 2006). Oil colour depends on the temperature to which it is submitted. Increase of colour intensity is due to accumulation of nonvolatile decomposition products such as oxidised triacylglycerols and FFA (Antoniassi et al., 1998).

Refined oils of both processes (Table 1$)$ were similar $(p>0.05)$ for FFA, PV, AV, TBA and LC values. PV, AV, TBA and LC increased after the deodorisation step.

\subsection{Fatty acids profiles}

The fatty acids profiles of carp oil from the refinement step are shown in Table 2. It can be verified that the crude and bleached oils were not significantly different between both processes. However, significant difference $(p<0.05)$ was observed for refined oils in relation to crude and bleached oils. Also, it can be verified that the refined oils were not significantly different between both processes. The major identified fatty acids were C18:1n-9 (oleic), C16:0 (palmitic), C16:1 (palmitoleic), C18:2n-6 (linoleic), and $\mathrm{C} 18: 3 n-3$ (linolenic), constituting around $67 \%$ of the total fatty acids of fishmeal and silage oils.

Palmitic acid was the predominant saturated fatty acid (SFA), accounting for about $50 \%$ of all SFA (Table 2). Oleic acid was identified as the most abundant monounsaturated fatty acid (MUFA) for refined oils. Palmitoleic acid was the second most abundant MUFA for crude, bleached and refined oils for both processes. High levels of oleic, palmitoleic, and arachidonic acids have been reported as a characteristic property of freshwater fish oils (Guler, Kiztanir, Aktumsek, Citil, \& Ozparlak, 2008). Linoleic and linolenic acids were the predominant polyunsaturated fatty acids (PUFA).

The increase of trans FA content for oleic and linoleic acids in refined oils is due to the high temperatures used in the deodorisation step. FA are labile molecules which, when exposed to heat treatment, can be lost through different chemical transformations (Berdeaux et al., 2007; Ceriane and Meirelless, 2007; Fournier et al., 2007). The initial content of trans PUFA in crude oils may increase in refined oils, due exclusively to deodorisation, since this reaction does not occur during preceding steps of the refinement process. In European countries, one quality parameter for refined edible oils is that the level of trans FA should be lower than $1.0 \%$ (Ceriane and Meirelless, 2007). In this manner, both refined oils obtained in this study were acceptable in relation to the trans level.

DHA and arachidonic (AA) contents in crude, bleached and refined oils were lower than those in carp oil cited by Rasoarahoma, Barnathan, Bianchini, and Gaydou (2004), of 6.7\% and 5.9\%, respectively, and higher than cited by Druzian, Marchesi, and Scamparini (2007), of $1.02 \%$ and $1.16 \%$ respectively. However, EPA content was higher than EPA contents quoted by these authors, of $3.4 \%$ and $2.4 \%$, respectively. The amount of EPA and DHA suggested for daily ingestion is within the range $200-1000 \mathrm{mg}$ (Inhamuns \& Franco, 2008). 
The reason for the variation in the results observed for EPA, DHA and AA is likely to be the feeding habits of the fish. The percentage of PUFA, such as EPA and DHA, in fish muscle, is dependent on their diets. Variations in fatty acid composition might be related to changes in the nutritional habits of the fish (Druzian et al., 2007; Inhamuns and Franco, 2008).

The lipid classes in carp oil from the refinement step are shown in Table 3. It can be verified that there was no significant difference for $\Sigma$ SFA and $\Sigma$ PUFA of crude and bleached oils for the fishmeal and ensilage processes. The refined oils in relation to crude and bleached oils showed significant differences $(p<0.05)$ for $\Sigma$ SFA, $\Sigma$ PUFA and $n-3 / n-6$ ratio for both processes. In general, fish are relatively low in SFA (<30\%), except for certain species; in Table 3 it can be verified that SFA content was around $27 \%$ for crude and bleached oils. MUFA contents of carp oil were higher than SFA in crude, bleached and refined fishmeal and silage oils (around 41.8\%). The publications of Guler et al. (2008) and Druzian et al. (2007) reported similar results for carp oil in the winter, of $41.1 \%$ and $43.1 \%$, respectively. PUFA contents in carp have been reported to vary over a very wide range, from $11.6-15.7 \%$ (Bieniarz, Koldras, Kaminski, \& Mejza, 2000) to 32.3-34.5\% (Geri, Poli, Gualtieri, Lupi, \& Parisi, 1995) of total fatty acids. In this work, PUFA contents of crude, bleached and refined fishmeal and silage oils (Table 3 ) were superior to that of oil examined by Druzian et al. (2007), of $23 \%$.

Refined oils presented a decrease in $\Sigma$ SFA content and an increase in the $\Sigma$ PUFA content in relation to the bleached oils due to the winterisation. This step is used to concentrate PUFAs; it is based on differences in melting points, using low-temperature crystallisation, which was originally developed to separate certain triacylglycerides (TAG), fatty acids, esters and other lipids which are highly soluble in organic solvents. Winterisation is a thermomechanical separation process where the high and low-melting TAG are separated by partial crystallisation, followed by filtration. Fat solubility in organic solvents decreases with increasing mean molecular weight and increases with increasing unsaturation (Ganga et al., 1998; Shahidi \& Wanasundara, 1998). Thus, the concentration of unsaturated and polyunsaturated fatty acids in refined oil occurred, with consequent decrease in $\Sigma$ SFA and increase in $\Sigma$ PUFA.

Table 3 shows that the unsaturated and polyunsaturated fatty acids (MUFA + PUFA) contents in refined fishmeal and silage oils represent $69.6 \%$ of the total fatty acids. Therefore, they are a rich source of unsaturated and polyunsaturated fatty acids. In this table, the $n-3 / n-6$ ratio in crude and bleached fishmeal and silage oils were 1.14 and 1.15 , respectively; for refined oils of the two processes the $n-3 / n-6$ ratio was 1.05 . This ratio is similar to the one cited by Guler et al. (2008) for carp oils. The $n-3 / n-6$ ratio in the total lipids of freshwater fish is usually between 0.5 and 3.8 (Henderson \& Tocher 1987). The $n-3 / n-6$ ratio has been suggested as a useful indicator for comparing relative nutritional values of fish oils. An increase in the human dietary $n-3 / n-6$ fatty acid ratio is essential in the diet, to help prevent coronary heart disease by reducing plasma lipids, and to reduce cancer risk. An increase in the dietary $n-3 / n-6$ ratio also seems to be effective in preventing toxic shock syndrome and cardiomyopathy (Guler et al., 2008).

Table 2

Fatty acid profiles (\%) of carp crude, bleached and refined oils obtained by two processes.

\begin{tabular}{|c|c|c|c|c|c|c|}
\hline \multirow[t]{2}{*}{ Fatty acids } & \multicolumn{3}{|l|}{ Fishmeal Oil } & \multicolumn{3}{|l|}{ Ensilage Oil } \\
\hline & Crude ${ }^{*}$ & Bleached ${ }^{*}$ & Deodorised ${ }^{*}$ & Crude $^{*}$ & Bleached $^{*}$ & Deodorised ${ }^{*}$ \\
\hline $11: 0$ & $0.08 \pm 0.01^{\mathrm{b}}$ & $0.08 \pm 0.01^{\mathrm{b}}$ & $0.06 \pm 0.01^{\mathrm{ab}}$ & $0.08 \pm 0.01^{\mathrm{b}}$ & $0.08 \pm 0.01^{b}$ & $0.05 \pm 0.01^{\mathrm{a}}$ \\
\hline $12: 0$ & $0.30 \pm 0.01^{\mathrm{ab}}$ & $0.29 \pm 0.01^{\mathrm{ab}}$ & $0.28 \pm 0.01^{\mathrm{a}}$ & $0.31 \pm 0.02^{\mathrm{ab}}$ & $0.32 \pm 0.02^{\mathrm{b}}$ & $0.29 \pm 0.01^{\mathrm{ab}}$ \\
\hline $13: 0$ & $0.24 \pm 0.01^{\mathrm{b}}$ & $0.23 \pm 0.01^{\mathrm{b}}$ & $0.20 \pm 0.01^{\mathrm{a}}$ & $0.25 \pm 0.01^{\mathrm{b}}$ & $0.23 \pm 0.02^{\mathrm{b}}$ & $0.20 \pm 0.01^{\mathrm{a}}$ \\
\hline $14: 0$ & $3.79 \pm 0.02^{\mathrm{b}}$ & $3.80 \pm 0.01^{b}$ & $3.11 \pm 0.02^{\mathrm{a}}$ & $3.82 \pm 0.03^{b}$ & $3.81 \pm 0.01^{\mathrm{b}}$ & $3.10 \pm 0.01^{\mathrm{a}}$ \\
\hline $15: 0$ & $1.20 \pm 0.03$ & $1.22 \pm 0.01$ & $1.20 \pm 0.01$ & $1.20 \pm 0.01$ & $1.21 \pm 0.01$ & $1.20 \pm 0.01$ \\
\hline $16: 0$ & $16.19 \pm 0.03^{b}$ & $16.20 \pm 0.02^{b}$ & $15.50 \pm 0.01^{\mathrm{a}}$ & $16.14 \pm 0.04^{b}$ & $16.16 \pm 0.01^{b}$ & $15.50 \pm 0.01^{a}$ \\
\hline $17: 0$ & $1.11 \pm 0.01^{\mathrm{b}}$ & $1.10 \pm 0.02^{\mathrm{b}}$ & $1.00 \pm 0.01^{\mathrm{a}}$ & $1.10 \pm 0.02^{\mathrm{b}}$ & $1.12 \pm 0.01^{b}$ & $1.00 \pm 0.01^{\mathrm{a}}$ \\
\hline 18:0 & $3.15 \pm 0.01^{c}$ & $3.13 \pm 0.02^{\mathrm{abc}}$ & $3.10 \pm 0.01^{a}$ & $3.17 \pm 0.02^{c}$ & $3.15 \pm 0.01^{c}$ & $3.11 \pm 0.01^{\mathrm{ab}}$ \\
\hline 20:0 & $0.25 \pm 0.01$ & $0.25 \pm 0.01$ & $0.26 \pm 0.01$ & $0.25 \pm 0.01$ & $0.24 \pm 0.01$ & $0.25 \pm 0.01$ \\
\hline 21:0 & $0.17 \pm 0.02$ & $0.18 \pm 0.01$ & $0.18 \pm 0.01$ & $0.18 \pm 0.01$ & $0.17 \pm 0.01$ & $0.17 \pm 0.01$ \\
\hline $22: 0$ & $0.18 \pm 0.02$ & $0.17 \pm 0.01$ & $0.18 \pm 0.02$ & $0.17 \pm 0.02$ & $0.17 \pm 0.01$ & $0.18 \pm 0.02$ \\
\hline $23: 0$ & $0.20 \pm 0.01$ & $0.20 \pm 0.01$ & $0.20 \pm 0.01$ & $0.20 \pm 0.01$ & $0.20 \pm 0.01$ & $0.20 \pm 0.01$ \\
\hline $14: 1 n-5$ & $0.17 \pm 0.01^{\mathrm{c}}$ & $0.16 \pm 0.01^{b c}$ & $0.14 \pm 0.01^{a}$ & $0.18 \pm 0.01^{c}$ & $0.15 \pm 0.03^{\mathrm{abc}}$ & $0.14 \pm 0.01^{\mathrm{ab}}$ \\
\hline $15: 1 n-5$ & $0.42 \pm 0.01^{\mathrm{b}}$ & $0.43 \pm 0.01^{\mathrm{b}}$ & $0.35 \pm 0.01^{\mathrm{a}}$ & $0.43 \pm 0.02^{\mathrm{b}}$ & $0.44 \pm 0.01^{\mathrm{b}}$ & $0.36 \pm 0.02^{\mathrm{a}}$ \\
\hline $16: 1 n-7$ & $8.08 \pm 0.04^{b}$ & $8.06 \pm 0.02^{b}$ & $7.64 \pm 0.01^{\mathrm{a}}$ & $8.04 \pm 0.03^{b}$ & $8.09 \pm 0.02^{b}$ & $7.65 \pm 0.01^{\mathrm{a}}$ \\
\hline $17: 1 n-7$ & $1.27 \pm 0.03^{b}$ & $1.28 \pm 0.01^{\mathrm{b}}$ & $1.20 \pm 0.01^{\mathrm{a}}$ & $1.30 \pm 0.03^{\mathrm{b}}$ & $1.26 \pm 0.04^{\mathrm{b}}$ & $1.43 \pm 0.01^{\mathrm{c}}$ \\
\hline $18: 1 n-9$ cis & $25.82 \pm 0.03^{a}$ & $25.84 \pm 0.01^{\mathrm{a}}$ & $26.45 \pm 0.01^{\mathrm{b}}$ & $25.80 \pm 0.02^{\mathrm{a}}$ & $25.82 \pm 0.01^{\mathrm{a}}$ & $26.47 \pm 0.01^{b}$ \\
\hline $18: 1 n-9$ trans & $0.23 \pm 0.02^{\mathrm{a}}$ & $0.25 \pm 0.01^{\mathrm{a}}$ & $0.35 \pm 0.01^{\mathrm{b}}$ & $0.21 \pm 0.02^{\mathrm{a}}$ & $0.23 \pm 0.02^{\mathrm{a}}$ & $0.33 \pm 0.01^{\mathrm{b}}$ \\
\hline $20: 1 n-9$ & $1.83 \pm 0.05^{\mathrm{a}}$ & $1.80 \pm 0.02^{\mathrm{a}}$ & $1.92 \pm 0.01^{\mathrm{b}}$ & $1.85 \pm 0.03^{\mathrm{a}}$ & $1.83 \pm 0.01^{\mathrm{a}}$ & $1.90 \pm 0.01^{\mathrm{b}}$ \\
\hline $22: 1 n-9$ & $0.08 \pm 0.01^{\mathrm{a}}$ & $0.08 \pm 0.01^{\mathrm{a}}$ & $0.18 \pm 0.02^{\mathrm{b}}$ & $0.08 \pm 0.02^{\mathrm{a}}$ & $0.07 \pm 0.01^{\mathrm{a}}$ & $0.18 \pm 0.01^{\mathrm{b}}$ \\
\hline $24: 1 n-9$ & $3.99 \pm 0.02^{\mathrm{b}}$ & $4.00 \pm 0.01^{\mathrm{b}}$ & $3.38 \pm 0.01^{\mathrm{a}}$ & $3.99 \pm 0.01^{b}$ & $3.98 \pm 0.01^{\mathrm{b}}$ & $3.39 \pm 0.01^{\mathrm{a}}$ \\
\hline $18: 2 n-6$ trans 9,12 & $0.31 \pm 0.01^{\mathrm{a}}$ & $0.31 \pm 0.01^{\mathrm{a}}$ & $0.51 \pm 0.01^{\mathrm{b}}$ & $0.30 \pm 0.01^{\mathrm{a}}$ & $0.31 \pm 0.01^{\mathrm{a}}$ & $0.52 \pm 0.01^{\mathrm{b}}$ \\
\hline $18: 2 n-6$ cis & $9.17 \pm 0.01^{a}$ & $9.17 \pm 0.01^{\mathrm{a}}$ & $9.68 \pm 0.01^{\mathrm{b}}$ & $9.17 \pm 0.01^{\mathrm{a}}$ & $9.16 \pm 0.01^{a}$ & $9.69 \pm 0.02^{b}$ \\
\hline $18: 3 n-6$ & $0.34 \pm 0.02^{\mathrm{abc}}$ & $0.33 \pm 0.01^{\mathrm{ab}}$ & $0.35 \pm 0.02^{\mathrm{bc}}$ & $0.32 \pm 0.01^{\mathrm{ab}}$ & $0.30 \pm 0.02^{\mathrm{a}}$ & $0.37 \pm 0.01^{\mathrm{c}}$ \\
\hline $18: 3 n-3$ & $7.16 \pm 0.01^{\mathrm{a}}$ & $7.17 \pm 0.01^{\mathrm{a}}$ & $7.52 \pm 0.01^{\mathrm{b}}$ & $7.17 \pm 0.01^{\mathrm{a}}$ & $7.18 \pm 0.01^{\mathrm{a}}$ & $7.50 \pm 0.01^{\mathrm{b}}$ \\
\hline $20: 2 n-6$ & $0.43 \pm 0.02^{\mathrm{a}}$ & $0.43 \pm 0.01^{\mathrm{a}}$ & $0.61 \pm 0.02^{\mathrm{b}}$ & $0.42 \pm 0.01^{\mathrm{a}}$ & $0.41 \pm 0.01^{\mathrm{a}}$ & $0.60 \pm 0.01^{\mathrm{b}}$ \\
\hline $20: 3 n-6$ & $0.42 \pm 0.02^{\mathrm{a}}$ & $0.41 \pm 0.01^{\mathrm{a}}$ & $0.59 \pm 0.01^{\mathrm{b}}$ & $0.43 \pm 0.02^{\mathrm{a}}$ & $0.42 \pm 0.01^{\mathrm{a}}$ & $0.58 \pm 0.01^{\mathrm{b}}$ \\
\hline $20: 3 n-3$ & $1.43 \pm 0.01^{\mathrm{a}}$ & $1.41 \pm 0.02^{\mathrm{a}}$ & $1.56 \pm 0.01^{\mathrm{b}}$ & $1.44 \pm 0.02^{\mathrm{a}}$ & $1.42 \pm 0.01^{\mathrm{a}}$ & $1.57 \pm 0.01^{\mathrm{b}}$ \\
\hline $20: 4 n-6(\mathrm{AA})$ & $1.24 \pm 0.02^{\mathrm{a}}$ & $1.23 \pm 0.01^{\mathrm{a}}$ & $1.70 \pm 0.01^{\mathrm{b}}$ & $1.22 \pm 0.01^{\mathrm{a}}$ & $1.21 \pm 0.01^{\mathrm{a}}$ & $1.68 \pm 0.01^{\mathrm{b}}$ \\
\hline $20: 5 n-3(\mathrm{EPA})$ & $3.82 \pm 0.01^{\mathrm{a}}$ & $3.83 \pm 0.01^{\mathrm{a}}$ & $3.90 \pm 0.01^{\mathrm{b}}$ & $3.81 \pm 0.2^{\mathrm{a}}$ & $3.83 \pm 0.01^{\mathrm{a}}$ & $3.91 \pm 0.01^{\mathrm{b}}$ \\
\hline $22: 2 n-6$ & $0.02 \pm 0.01^{\mathrm{a}}$ & $0.02 \pm 0.01^{\mathrm{a}}$ & $0.07 \pm 0.02^{\mathrm{b}}$ & $0.02 \pm 0.01^{\mathrm{a}}$ & $0.02 \pm 0.01^{\mathrm{a}}$ & $0.07 \pm 0.02^{\mathrm{b}}$ \\
\hline $22: 6 n-3(\mathrm{DHA})$ & $1.20 \pm 0.02^{\mathrm{a}}$ & $1.20 \pm 0.01^{\mathrm{a}}$ & $1.30 \pm 0.01^{\mathrm{b}}$ & $1.20 \pm 0.01^{\mathrm{a}}$ & $1.22 \pm 0.01^{\mathrm{a}}$ & $1.31 \pm 0.01^{\mathrm{b}}$ \\
\hline$\Sigma \mathrm{nu}{ }^{* *}$ & $5.73 \pm 0.30^{\mathrm{b}}$ & $5.76 \pm 0.38^{b}$ & $5.11 \pm 0.50^{\mathrm{a}}$ & $5.71 \pm 0.20^{b}$ & $5.79 \pm 0.22^{\mathrm{b}}$ & $5.10 \pm 0.26^{\mathrm{a}}$ \\
\hline
\end{tabular}

AA: arachidonic acid; EPA: eicosapentanoic acid; DHA: docosahexanoic acid.

Different superscript letters in the same line are significantly different $(p<0.05)$.

Mean value \pm standard $(n=3)$.

$\Sigma$ sum of unidentified fatty acids. 
Table 3

Lipids classes (\% of total fatty acids) in carp crude, bleached and refined oils obtained by two processes.

\begin{tabular}{|c|c|c|c|c|c|c|}
\hline & \multicolumn{3}{|l|}{ Fishmeal oil } & \multicolumn{3}{|l|}{ Ensilage oil } \\
\hline & Crude & Bleached & Deodorised & Crude & Bleached & Deodorised \\
\hline$\Sigma \mathrm{SFA}^{*}$ & $26.86 \pm 0.19^{b}$ & $26.85 \pm 0.15^{b}$ & $25.27 \pm 0.14^{\mathrm{a}}$ & $26.87 \pm 0.20^{b}$ & $26.86 \pm 0.14^{b}$ & $25.25 \pm 0.13^{a}$ \\
\hline$\Sigma$ MUFA $^{* *}$ & $41.89 \pm 0.20$ & $41.90 \pm 0.11$ & $41.83 \pm 0.22$ & $41.88 \pm 0.15$ & $41.87 \pm 0.16$ & $41.85 \pm 0.10$ \\
\hline$\Sigma$ PUFA $^{* * *}$ & $25.54 \pm 0.15^{a}$ & $25.51 \pm 0.12^{\mathrm{a}}$ & $27.79 \pm 0.14^{b}$ & $25.50 \pm 0.13^{a}$ & $25.48 \pm 0.12^{\mathrm{a}}$ & $27.80 \pm 0.13^{b}$ \\
\hline$n-3$ & $13.61 \pm 0.10^{a}$ & $13.61 \pm 0.15^{a}$ & $14.28 \pm 0.10^{b}$ & $13.62 \pm 0.10^{a}$ & $13.65 \pm 0.10^{a}$ & $14.29 \pm 0.10^{b}$ \\
\hline$n-6$ & $11.93 \pm 0.10^{\mathrm{a}}$ & $11.90 \pm 0.10^{\mathrm{a}}$ & $13.51 \pm 0.10^{b}$ & $11.88 \pm 0.15^{a}$ & $11.83 \pm 0.10^{a}$ & $13.51 \pm 0.10^{\mathrm{b}}$ \\
\hline$n-3 / n-6$ & $1.14 \pm 0.01^{b}$ & $1.14 \pm 0.01^{\mathrm{b}}$ & $1.05 \pm 0.01^{\mathrm{a}}$ & $1.15 \pm 0.01^{b}$ & $1.15 \pm 0.01^{\mathrm{b}}$ & $1.05 \pm 0.01^{\mathrm{a}}$ \\
\hline
\end{tabular}

Mean value \pm standard error $(n=3)$.

Different superscript letters in the same line are significantly different $(p<0.05)$.

* $\Sigma$ SFA: sum of unsaturated.

** $\Sigma$ MUFA: sum of monounsaturated.

*** PUFA: sum of polyunsaturated.

\section{Conclusions}

In this study, carp (Cyprinus carpio) crude oils obtained by the ensilage and fishmeal processes showed significant differences $(p<0.05)$ for FFA, TBA, AV, PC and LC values. Also, differences $(p<0.05)$ were observed between the crude and bleached oils. The FFA, TBA, AV, PV and LC values decreased after bleaching of the crude oils. The refined oils obtained by both processes did not differ. Carp oil refinement improved the fish oil characteristics, because it removed components that cause colour, free fatty acids and lipid oxidation products.

The fatty acids profiles of refined carp oils were significantly different $(p<0.05)$ in relation to crude oil and bleached oils for both processes. Refinement of the carp oils decreased the $\Sigma$ SFA content and increased the $\Sigma$ PUFA content; this occurred due to the winterisation step. The unsaturated and polyunsaturated fatty acids (MUFA + PUFA) contents in refined fishmeal and silage oils were around $69.6 \%$ of the total fatty acids. In this study, the $n-3$ / $n-6$ ratio was 1.05 for refined oils, similar to values cited in the literature. Therefore, based on the results obtained in this work, carp viscera refined oil can be considered a rich source of essential fatty acids of the $n-3$ and $n-6$ series.

\section{References}

Aidos, I., Schelvus-Smit, R., Veldnan, M. B., Luten, J., Padt, A. V. D., \& Boom, R. M. (2003). Chemical and sensory evaluation of crude oil extracted from Herring byproducts from different processing operations. Journal of Agricultural and Food Chemistry, 50, 1897-1903.

Antoniassi, R., Esteves, W., \& Meirelles, J. A. (1998). Pretreatment of corn oil for physical refining. Journal of the American Oil Chemists Society, 75(10), 1411-1415.

American Oil Chemists Society (AOCS) (1980). Official and Tentative Methods of American Oil Chemists' Society (3rd ed.).

American Oil Chemists Society (AOCS) (1997). Official Methods and Recommended Practices of the American Oil Chemists' Society.

Berdeaux, O., Fournier, V., Lambelet, P., Dionisi, F., Sebedio, J. L., \& Destaillats, F. (2007). Isolation and structural analysis of the cyclic fatty acid monomers formed from eicosapentaenoic and docosahexaenoic acids during fish oil deodorization. Journal of Chromatography A, 1138, 216-224.

Bieniarz, K., Koldras, M., Kaminski, J., \& Mejza, T. (2000). Fatty acids and cholestorol in some freshwater fish species in Poland. Folia Universitas Agriculture Stetinensis, 27, 21-44.

Boran, G., Karaçam, H., \& Boran, M. (2006). Changes in the quality of fish oils due to storage temperature and time. Food Chemistry, 98, 693-698.

Box, G. E. P., Hunter, W. G., \& Hunter, J. S. (1978). Statistics for Experiments: An Introduction to Design. Data Analysis and Model Building, New York, USA: John Wiley \& Sons.

Ceriane, R., \& Meirelless, J. A. (2007). Formation of trans PUFA during deodorization of canola oil: A study through computational simulation. Chemical Engineering and Processing, 46, 375-385.

Chantachum, S., Benjakul, S., \& Sriwirat, N. (2000). Separation and quality of fish oil precooked and non-precooked tuna heads. Food Chemistry, 69, 2089-2294.

Druzian, J. I., Marchesi, C. M., \& Scamparini, A. R. P. (2007). Fatty acid profile and proximate composition of carp (Cyprinus carpio) feed artificial food and pig manure. Ciência Rural, 37, 539-544.

Fournier, V., Destaillats, F., Hug, B., Golay, P. A., Joffre, F., Juaneda, P., et al. (2007). Quantification of eicosapentaenoic and docosahexaenoic acidgeometrical isomers formed during fish oil deodorization by gas-liquid chromatography. Journal of Chromatography A, 1154, 353-359.

Ganga, A., Nieto, S., Sanhuez, J., Romo, C., Speisky, H., \& Valenauela, A. (1998) Concentration and stabilization of $n-3$ polyunsaturadet fatty acids sardine oil. Journal of the American Oil Chemists Society, 75(6), 733-736.

Geri, G., Poli, B. M., Gualtieri, M., Lupi, P., \& Parisi, G. (1995). Body traits and chemical composition of muscle in the common carp (Cyprinus carpio) as influenced by age and rearing environment. Aquaculture, 129, 329-333.

Guler, G. O., Kiztanir, B., Aktumsek, A., Citil, O. B., \& Ozparlak, H. (2008) Determination of the seasonal changes on total fatty acid composition and 3 / 6 ratios of carp (Cyprinus carpio L.) muscle lipids in Beysehir Lake (Turkey). Food Chemistry, 108, 689-694.

Hafidi, A., Pioch, P., \& Ajana, H. (2005). Membrane-based simultaneous degumming and deacidification of vegetable oils. Innovative Food Science and Emerging Technologies, 6, 203-212.

Hamilton, R. J., Kalu, C., McNeill, G. P., Padley, F. B., \& Pierce, J. H. (1988). Effects of tocopherols, ascorbyl palmitate and lecithin on autoxidation of fish oil. Journal of the American Oil Chemists' Society, 75(7), 813-821.

Henderson, R. J., \& Tocher, D. R. (1987). The lipid composition and biochemistry of freshwater fish. Progress in Lipid Research, 26(4), 281-347.

Hidalgo, A., Brandolini, A., Pompei, C., \& Piscozzi, R. (2006). Carotenoids and tocols of einkorn wheat (Triticum monococcum ssp. monococcum L.). Journal of Cereal Science, 44, 182-193.

Immanuel, G., Sathasivan, S., Skankar, S., Peter, P. M. J., \& Palavesam, A. (2009) Processing and characterization of low cost Balistid fish Suffamen capistratus liver oil for purpose. Food Chemistry, 115, 430-435.

Inhamuns, A. J., \& Franco, M. R. B. (2008). EPA and DHA quantification in two species of freshwater fish from Central Amazonia. Food Chemistry, 107, 587-591.

Luterotti, S., Franko, M., \& Bicanic, D. (1999). Ultrasensitive determination of carotene in fish oil-based supplementary drugs by HPLC-TLS. Journal of Pharmaceutical Biomedical Analysis, 21, 901-909.

Manral, M., Pandey, M. C., Jayathilakan, K., Radhakrishna, K., \& Bawa, A. S. (2008) Effect of fish (Catla catla) fring on the quality characteristics of sunflower oil. Food Chemistry, 106, 634-639.

Metcalfe, L. D. A. A., \& Schimitz, J. R. (1966). Rapid preparation of fatty acid esters from lipids for gas liquid chromatography. Analytical Chemistry, 38, 510.

Rasoarahoma, J. R., Barnathan, G., Bianchini, J. P. \& Gaydou, E. M. (2004). Annual evolution of fatty acid profile from muscle lipids of the common carp (Cyprinus carpio) in Madagascar inland waters. Journal of Agricultural and Food Chemistry $52,7339-7344$

Reece, P. (1981). Recovery of high quality oil from mackerel and sprat by silage process. Journal of the Science of Food and Agriculture, 32, 531-538.

Rossi, M., Gianazza, M., Alamprese, C., \& Stanga, F. (2003). The role of bleaching clays and synthetic sílica in palm oil physical refining. Food Chemistry, 82, 291-293.

Sathivel, S., Prinyawiwatkul, W., King, J. M., Grimm, C. C., \& Lloyd, S. (2003). Oil production from catfish viscera. Journal of the American Oil Chemists' Society, 80 277-382.

Shahidi, F., \& Wanasundara, N. U. (1998). Omega-3 concentrates: Nutritional aspects and production technologies. Trends in Foods Science E Technology, 9, 230-240.

Vandeputte, M., Kocour, M., Mauger, S., Rodina, M., Launay, A., Gela, D., et al. (2008). Genetic variation for growth at one and two summers of age in the common carp (Cyprinus carpio L.): Heritability estimates and response to selection. Aquaculture, 277, 7-13.

Vyncke, W. (1970). Direct determination of the thiobabituric acid value in trichoroacetic acid extracts of fish as a measure of oxidative rancidity. FetteSeifen Anstrichmittel, 12, 1084-1087.

Windsor, M. \& Barlow, S. (1984). Introduction to the Fishing Products (pp. 99-109). Zaragosa, Spain: Acribia Publishing House.

Zhong, Y., Madhujith, T., Mahfouz, N., \& Shahidi, F. (2007). Compositiona characteristics of muscle and visceral oil from steelhead trout and their oxidative stability. Food Chemistry, 104, 602-608.

Zhou, S., Paulson, A. T., \& Ackman, R. G. (1995). Release of free fatty acids from lipids during ensilation of herring mince. the possible role of ethoxyquin. Journal of Food Lipids, 3, 121-134. 